\title{
Fuzzy Logic Control based Three Phase Shunt Active Filter for Voltage Regulation and Harmonic Reduction
}

\author{
G. Jayakrishna \\ Department of Electrical and Electronics Engineering \\ Siddharth Institute of Engineering and Technology \\ Puttur, Chittoor(Dist), \\ Andhrapradesh, India.
}

\author{
K.S.R.Anjaneyulu \\ Professor of Electrical \& Electronics Engineering \\ Director, Research \& Development Cell, \\ Jawaharlal Nehru Technological University, \\ Anantapur, India
}

\begin{abstract}
This paper studies a Fuzzy Logic Control Based (FLCB) Shunt Active Filter (SAF) capable of reducing the total harmonics distortion (THD) in Power System (PS). SAF is one of the key controllers in Flexible Alternating Current Transmission System (FACTS) to control the transmission line voltage and can be used in PS to enhance the power transmission capacity and extend the transient stability. In order to improve the power factor, compensate the reactive power and suppress the total harmonic distortion (THD) drawn from a Non-Linear Diode Rectifier Load (NLDRL) of SAF, we propose a Hysteresis Current Pulse Width Modulation (HCPWM) technique which is used as control for the switches of the Voltage Source Inverter (VSI) or SAF. The synchronous reference D-Q frame theory is used to generate the reference compensating currents for SAF. A fuzzy logic based control is developed to regulate the voltage of the DC capacitor. The system with control scheme is implemented in Matlab/Simulink. The simulation results show the effectiveness of the proposed method for harmonic damping and voltage regulation.
\end{abstract}

\section{KEYWORDS}

Power systems, Shunt active filter, Fuzzy logic based control, Voltage regulation, Hysteresis current pulse width modulation, D-Q reference frame theory.

\section{INTRODUCTION}

Harmonic distortion (HD) is one of the main power quality problems frequently encountered by the utilities. The harmonic problems in the power supply are caused by the non-linear characteristics based loads. The presence of harmonics leads to transformer heating, electromagnetic interference and solid state device malfunctioning. Hence, it is necessary to reduce the dominant harmonics below $5 \%$ as specified in IEEE 519-1992 harmonic standard [1].

Harmonic amplification is one of the most serious problems. It is caused by harmonic resonance between line inductance and power factor correction (PFC) capacitors installed by consumers. Active filters for damping out harmonic resonance in industrial and utility power distribution systems have been researched [1]-[5].

Tradionally based, passive L-C filters were used to eliminate line harmonics in [2]-[4]. However, the passive filters have the demerits of fixed compensation, bulkiness and occurrence of resonance with other elements. The recent advances in power semiconductor devices have resulted in the development of Active Power Filters (APF) for harmonic suppression. Various topologies of active filters have been proposed for harmonic mitigation. The shunt APF based on Voltage Source Inverter
(VSI) structure is an attractive solution to harmonic current problems. The SAF is a pulse width modulated (PWM) VSI that is connected in parallel with the load. It has the capability to inject harmonic current into the AC system with the same amplitude but opposite phase than that of the load [1]-[2]. The principal components of the APF are the VSI, a DC energy storage device that in this case is capacitor, a coupling transformer and the associated control circuits. The performance of an active filter depends mainly on the technique used to compute the reference current and the control method used to inject the desired compensation current into the line.

There are two major approaches that have emerged for the harmonic detection [2], namely, time domain and the frequency domain methods. The frequency domain methods include, Discrete Fourier Transform (DFT), Fast Fourier Transform (FFT), and Recursive Discrete Fourier Transform (RDFT) based methods. The frequency domain methods require large memory, computation power and the results provided during the transient condition may be imprecise [4]. On the other hand, the time domain methods require less calculation and are widely followed for computing the reference current. The two mostly used time domain methods are synchronous reference (d-q-0) theory and instantaneous real-reactive power (p-q) theory. Synchronous reference (d-q-0) theory is followed in this work.

There are several current control strategies proposed in the literature [5]-[7], [9]-[10], namely, PI control, Average Current Mode Control (ACMC), Sliding Mode Control (SMC) and hysteresis control. Among the various current control techniques, hysteresis control is the most popular one for active power filter applications. Hysteresis current control [6] is a method of controlling a voltage source inverter so that the output current is generated which follows a reference current waveform in this paper.

Generally, PI controller [7] is used to control the DC bus voltage of $\mathrm{SAF}$. The PI controller based approach requires precise linear mathematical model which is difficult to obtain. Also, it fails to perform satisfactorily under parameter variations, non-linearity, and load disturbances. This paper proposes a fuzzy logic controller for D.C bus voltage control [8]. Computer simulations are carried out on a sample power system to demonstrate the effectiveness of the proposed approach in suppressing the harmonics. 


\section{CONTROL METHOD FOR SAF}

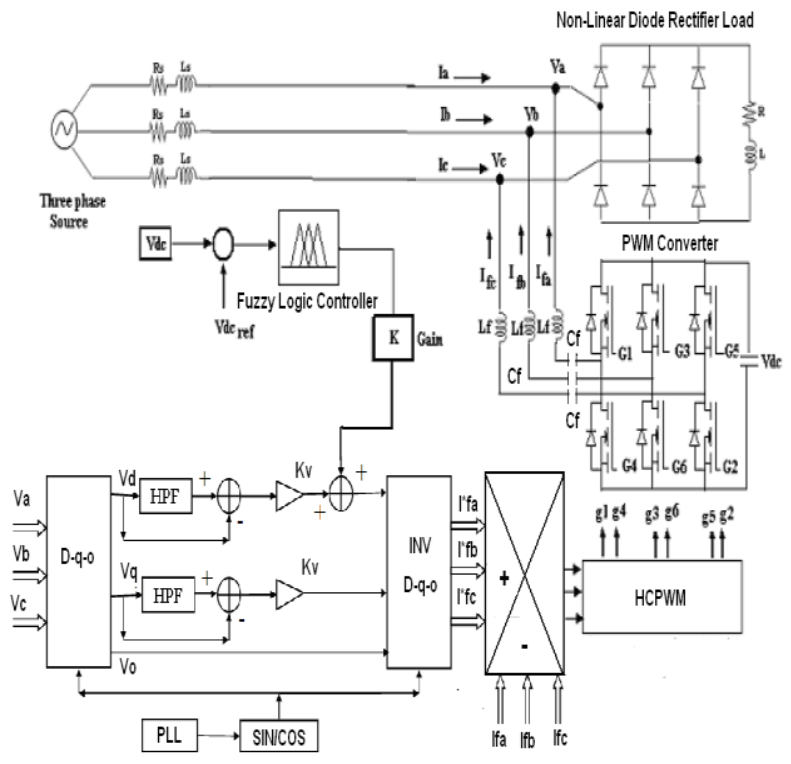

Fig. 1 Active Power Filter with the proposed control technique.

The performance of the active filter mainly depends on the methodology adopted to generate the reference current and the control strategy adopted to generate the gate pulses. The block diagram representation of the proposed control technique for the SAF is shown in Fig.1. The control strategy is implemented in three stages. In the first stage, the essential voltage signals are measured to gather accurate system information. In the second stage, compensating currents are derived based on synchronous reference D-Q theory. In the third stage, the gating signals for the solid-state devices are generated using HCPWM control method.

There are several methods to extract the harmonic components from the detected three-phase waveforms. Among them, the so-called D-Q theory based on time domain has been widely applied to the harmonic extraction circuit of SAF. The detected three-phase voltage is transformed into the D- Q-0 co-ordinates as shown in Fig.1. Two first order digital high pass filters (HPFs) with the same cut off frequency as $20 \mathrm{~Hz}$ extract the dc component $\mathrm{V}_{\mathrm{hd}}{ }^{*}, \mathrm{~V}_{\mathrm{hq}}{ }^{*}$ and $\mathrm{V}_{0}$ which corresponds to the fundamental frequency in the coordinates [7].

In line - voltage regulation part is performed by a feedback control. Two co-ordinates $\mathrm{V}_{\mathrm{d}}$ and $\mathrm{V}_{\mathrm{q}}$ is compared with harmonic extracted voltage $\mathrm{V}_{\mathrm{hd}}{ }^{*}$ and $\mathrm{V}_{\mathrm{hq}}{ }^{*}$. A gain $\mathrm{K}_{\mathrm{V}}$ amplifies and to produce current references for harmonic damping $\mathrm{I}_{\mathrm{hd}}, \mathrm{I}_{\mathrm{hq}}$, and $\mathrm{I}_{0}$ as shown in equation (1), equation (2) and equation (3). The current reference for the voltage - source inverter is the sum of the current references from the three parts, as follows:

$\mathrm{I}_{\mathrm{fd}}^{*}(\mathrm{~s})=\mathrm{K}_{\mathrm{v}}\left(\mathrm{G}_{\mathrm{h}} \mathrm{V}_{\mathrm{hd}}{ }^{*}-\mathrm{V}_{\mathrm{d}}\right)+\operatorname{Preg}$ or $\left(\mathrm{V}_{\mathrm{dc}} *-\mathrm{V}_{\mathrm{dc}}\right) * \mathrm{~K}$

$$
\mathrm{I}_{\mathrm{fq}}^{*}(\mathrm{~s})=\mathrm{K}_{\mathrm{v}}\left(\mathrm{G}_{\mathrm{h}} \mathrm{V}_{\mathrm{hq}}{ }^{*}-\mathrm{V}_{\mathrm{q}}\right)
$$

$$
\mathrm{I}_{0}^{*}(\mathrm{~s})=1 / 3\left(\mathrm{~V}_{\mathrm{a}}+\mathrm{V}_{\mathrm{b}}+\mathrm{V}_{\mathrm{c}}\right)
$$

The obtained current reference is converted in to three phase current reference by inverse D - Q transformation $\mathrm{I}_{\mathrm{fa}}^{*}, \mathrm{I}_{\mathrm{fb}}^{*}$, and $\mathrm{I}_{\mathrm{fc}}^{*}$. The three phase reference filter current is compared with the active filter compensating current extracted from ac system. Thus three phase filter currents $\mathrm{I}_{\mathrm{fa}}, \mathrm{I}_{\mathrm{fb}}$, and $\mathrm{I}_{\mathrm{fc}}$ are produced. The obtained reference current is given to a HCPWM scheme, which is used to generate controlled gate signal for SAF.

HCPWM controller derives the switching signals of the inverter power switches in a manner that reduces the current error. The switches are controlled asynchronously to ramp the current through the inductor up and down so that it follows the reference. The current ramping up and down between two limits is illustrated in Fig.2. When the current through the inductor exceeds the upper hysteresis limit a negative voltage is applied by the inverter to the inductor. This causes the current in the inductor to decrease. Once the current reaches the lower hysteresis limit, a positive voltage is applied by the inverter to the inductor and this causes the current to increase and the cycle repeats.

The current controllers of the three phases are designed to operate independently. Each current controller determines the switching signals to the inverter. The switching logic for phase A is formulated as below;

If $i f a<\left(i^{*} f a-\mathrm{HB}\right)$ upper switch (G1) is OFF and lower switch (G4) is ON

If $i f a<\left(i^{*} f a+\mathrm{HB}\right)$ upper switch (G1) is ON and lower switch (G4) is $\mathrm{OFF}$

In the same fashion, the switching of phase $\mathrm{B}$ and $\mathrm{C}$ devices are derived.

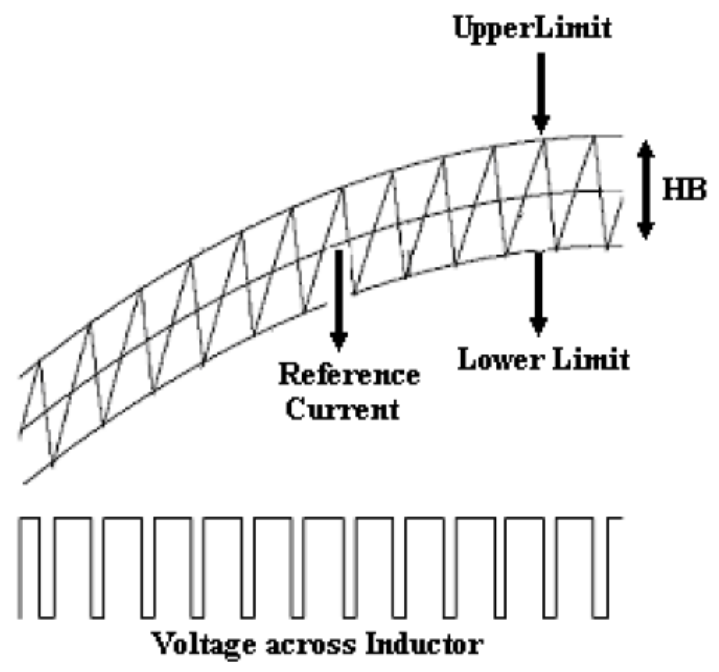

Fig.2. Hysteresis Current PWM Control Operation Waveform. 
The DC side of the inverter is connected to a capacitor. The DC capacitor provides a constant DC voltage and the real power necessary to supply the losses of the system. In the steady state, the real power supplied by the source should be equal to the real power demand of the load plus a small power to compensate the losses in the active filter. Thus, the DC capacitor voltage can be maintained at a reference value. However, when the load condition changes the real power balance between the mains and the load will be disturbed. The real power difference is to be compensated by the DC capacitor. This changes the DC capacitor voltage away from the reference voltage. A fuzzy logic controller is applied to maintain the constant voltage across the capacitor by minimizing the error between the capacitor voltage and the reference voltage.

Fig. 3 shows the simplified circuit of distribution system under noload conditions. In the feeder simulator, harmonic is generated by a NLDRL connected at the bus which produces an amount of harmonic voltage. When a lossless line is assumed, the characteristic impedance of the feeder simulator can be calculated as shown in equation (4).

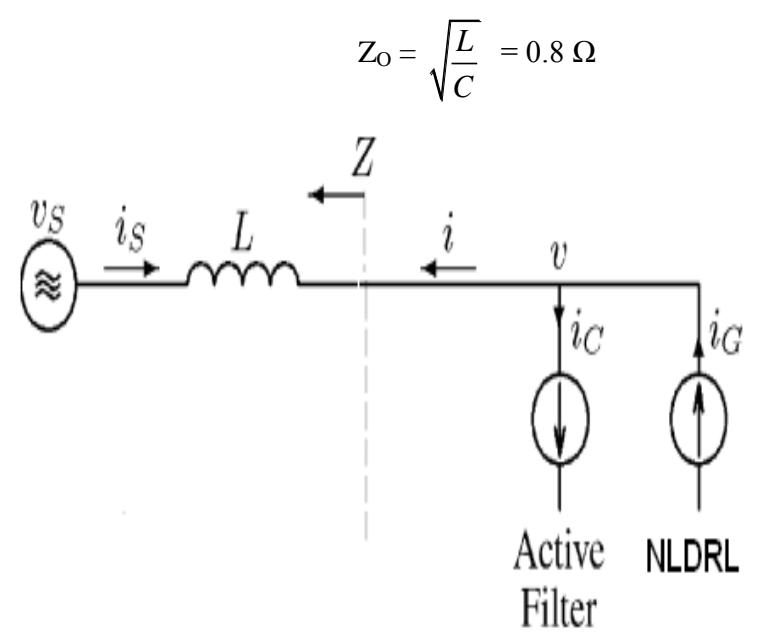

Fig. 3. Simplified circuit of the distribution system.

\section{DESIGN OF DC BUS FUZZY LOGIC CONTROLLER}

To design the FLC, variables which can represent the dynamic performance of the plant to be controlled should be chosen as the inputs to the controller. It is common to use the output error (e) and the rate of change of error (e') as controller inputs. In the case of the fuzzy logic based DC voltage control, the capacitor voltage deviation and its derivative are considered as the inputs of the FLC and the real power (Preg) requirement for voltage regulation is taken as the output of the FLC. The input and output variables are converted into linguistic variables. In this case, seven fuzzy subsets, NL(Negative Large), NM (Negative Medium), NS (Negative Small), ZE (Zero), PS (Positive Small), PM (Positive Medium) and PL ( Positive large) have been chosen. Membership functions used for the input and output variables used here are shown in Fig.4. As both inputs have seven subsets, a fuzzy rule base formulated for the present application is given in Table $\mathbf{1}$.
Table 1. Fuzzy Control Rule

\begin{tabular}{|l|l|l|l|l|l|l|l|}
\hline \multicolumn{1}{|l}{ de } & NL & NM & NS & ZE & PS & PM & PL \\
\hline NL & NL & NL & NL & NL & NM & NS & ZE \\
\hline NM & NL & NM & NM & NM & NS & Z & PS \\
\hline NS & NL & NM & NS & NS & ZE & PS & PM \\
\hline ZE & NL & NM & NS & ZE & PS & PM & PL \\
\hline PS & NM & NS & ZE & PS & PS & PM & PL \\
\hline PM & NS & ZE & PS & PM & PM & PM & PL \\
\hline PL & ZE & PS & PM & PL & PL & PL & PL \\
\hline PL & ZE & PS & PM & PL & PL & PL & PL \\
\hline
\end{tabular}

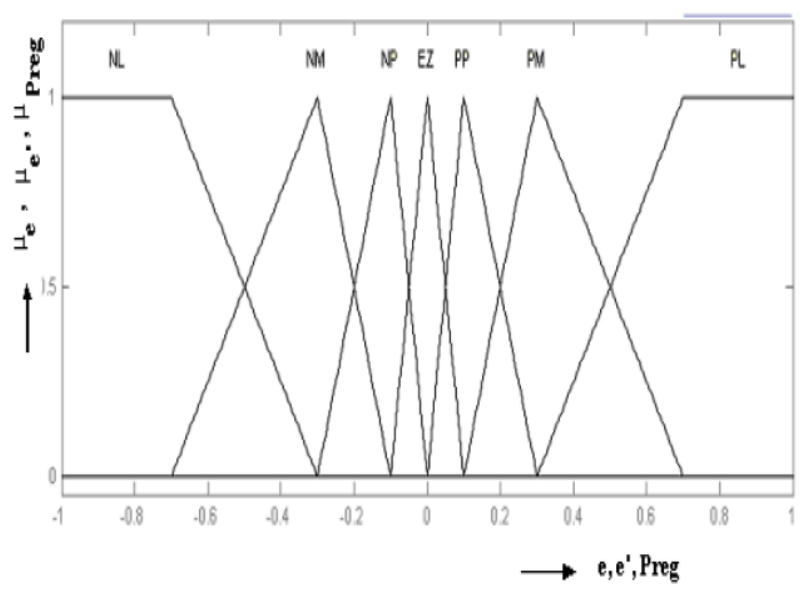

Fig. 4. Memberships function for the input and output variables.

\section{SIMULATION RESULTS}

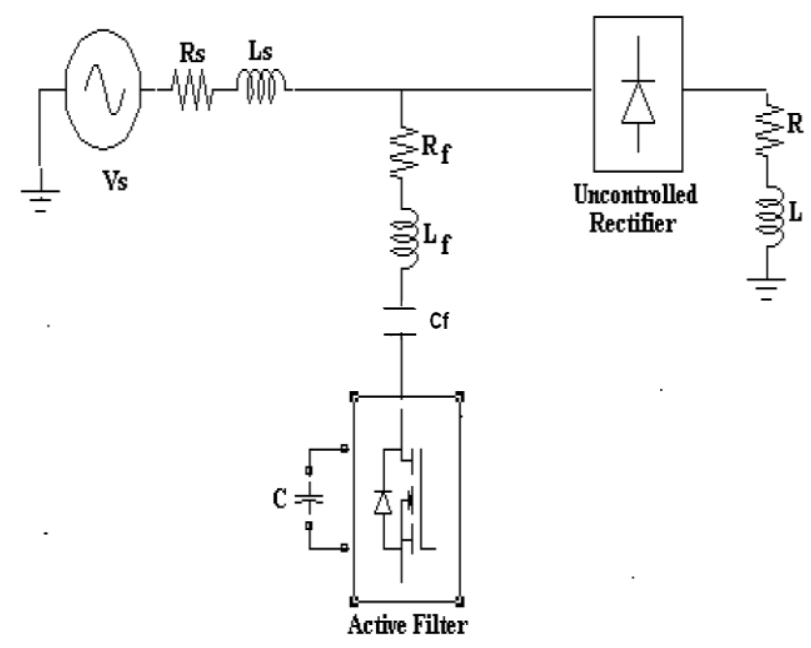

Fig. 5. Test Power System. 
Table 2. Circuit parameters used for the SAF.

\begin{tabular}{|l|c|}
\hline \multicolumn{1}{|c|}{ Parameters name } & Numerical Value \\
\hline Source voltage Vs & $\begin{array}{l}2.828 \mathrm{kV}, 50 \mathrm{~Hz} \\
\text { (line r.m.s) }\end{array}$ \\
\hline DC Capacitors & $4700 \mu \mathrm{F}$ \\
\hline $\begin{array}{l}\text { D.C capacitor reference } \\
\text { voltage }\end{array}$ & $400 \mathrm{~V}$ \\
\hline switching frequency & $20 \Omega, 0.1 \mathrm{mH}$ \\
\hline $\begin{array}{l}\text { Diode rectifier Non- linear } \\
\text { Load resistance and } \\
\text { inductance }\end{array}$ & $2 \mathrm{mH}, 0.1 \mathrm{ohm}$ and $100 \mu \mathrm{F}$ \\
\hline $\begin{array}{l}\text { Filter inductance, resistance } \\
\text { and capacitor }\end{array}$ & $1 \mathrm{mH}, 0.1 \mathrm{ohm}$ \\
\hline $\begin{array}{l}\text { Source resistance and } \\
\text { inductance }\end{array}$ & \multicolumn{2}{|c|}{} \\
\hline
\end{tabular}

This section presents the details of the simulation carried out to demonstrate the effectiveness of the proposed control strategy for the SAF to reduce the harmonics. Fig. 5 shows the test system used to carry out the analysis. The test system consists of a three phase voltage source, and an uncontrolled rectifier with RL load. The active filter is connected to the test system through an inductor $\mathrm{L}_{\mathrm{f}}$ and Capacitor $\mathrm{C}_{\mathrm{f}}$. The values of the circuit elements used in the simulation are listed in Table 2. The Matlab/Simulink is used to simulate the test power system with and without the proposed SAF.

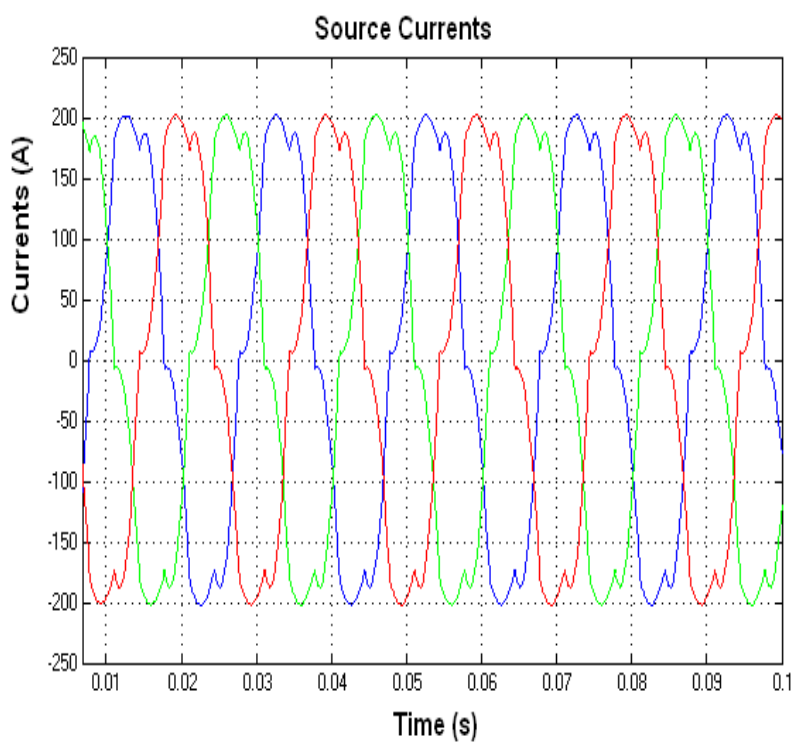

Fig.6. Three phase source currents of test power system without SAF.

Figs. 6 and 7 show the three phase source voltages and currents of test power system without SAF. It can be seen that the harmonic has severely disturbed the voltages as well as currents. Fig. 8 shows the harmonic spectrum of phase-a source current without SAF. It can be found that the THD is $26.35 \%$ for proposed test system.

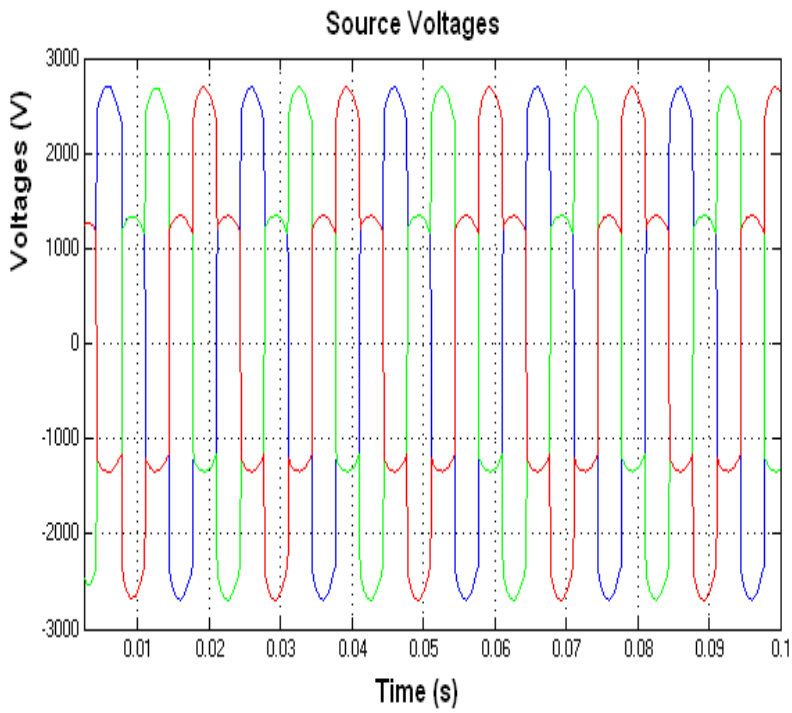

Fig.7. Three phase supply voltages of test power system without SAF.

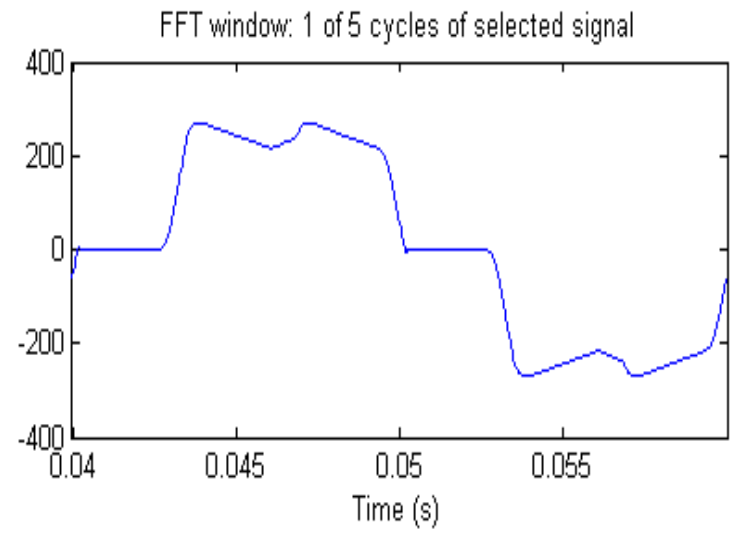

Fundamental $(5 \mathrm{OHz})=266.6, \mathrm{THD}=26.35 \%$

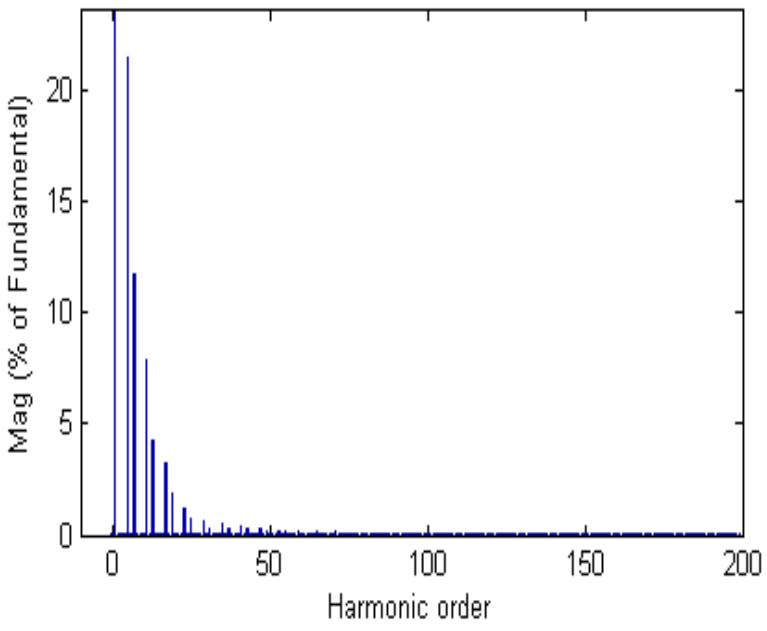

Fig.8. Harmonic spectrum of phase a source current without SAF. 


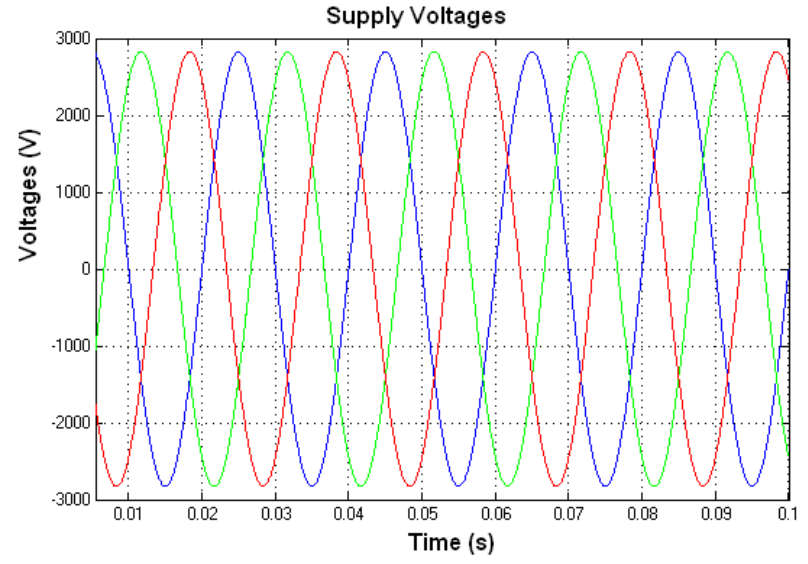

Fig.9. Three phase supply voltages of test power system with SAF.

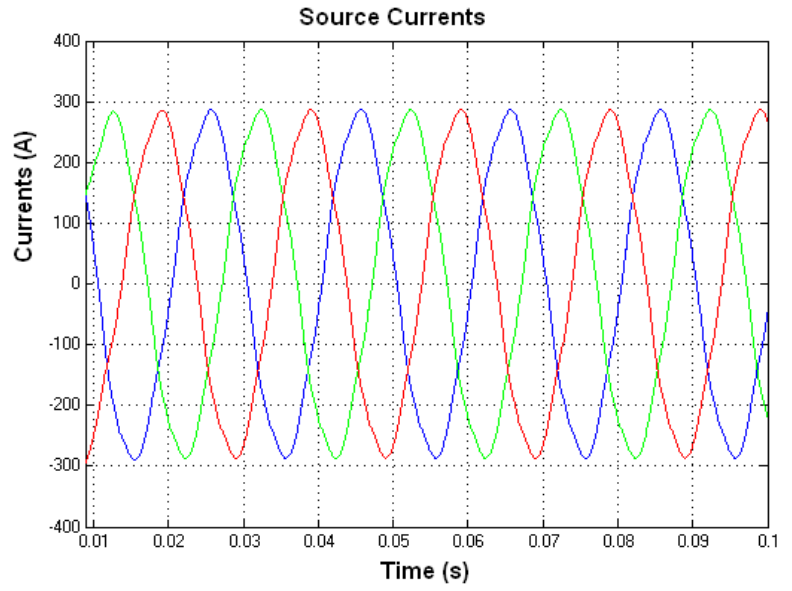

Fig.10. Three phase source currents of test power system with SAF.

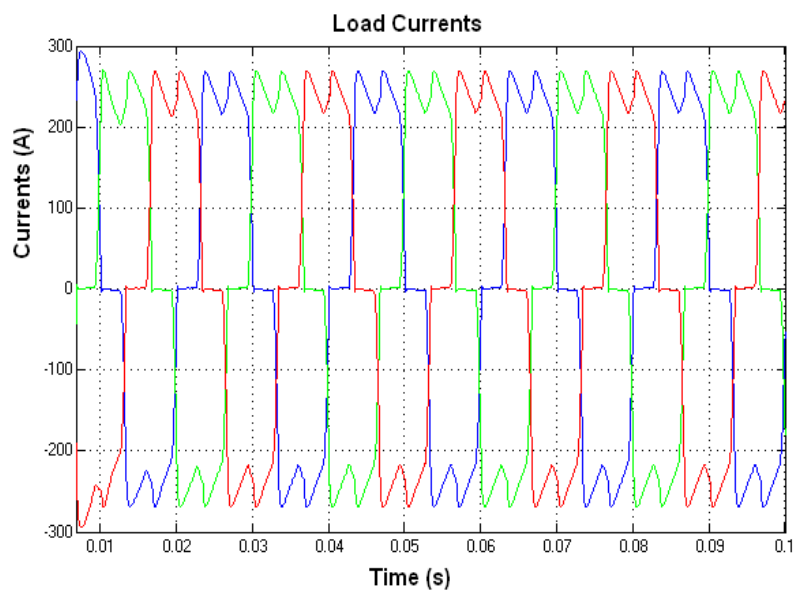

Fig.11. Distorted three phase load currents of test power system with SAF.

Figs. 9 and 10 show the three phase voltages and currents of test power system with SAF. It could be found that the wave shapes of the voltages and currents are in pure sinusoidal form.

The three phase load current waveforms in the presence of the filter are shown in Fig. 11 and the three phase compensated or filtered currents for SAF are shown in Fig. 12.

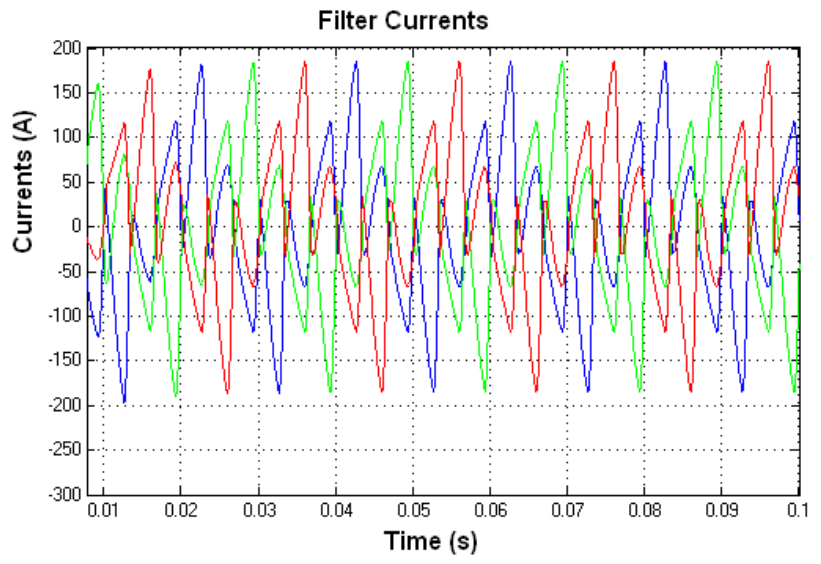

Fig. 12. Three phase Filter currents of test power system with SAF.

FFT window: 1 of 5 cycles of selected signal

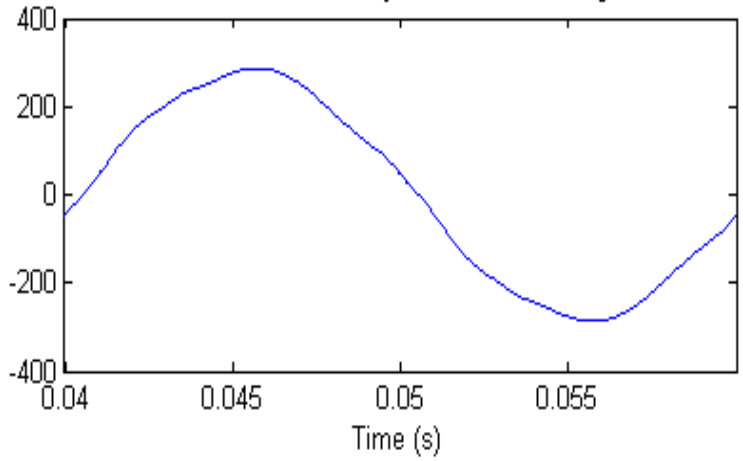

Fundamental $(50 \mathrm{~Hz})=281.3, \mathrm{THD}=3.56 \%$

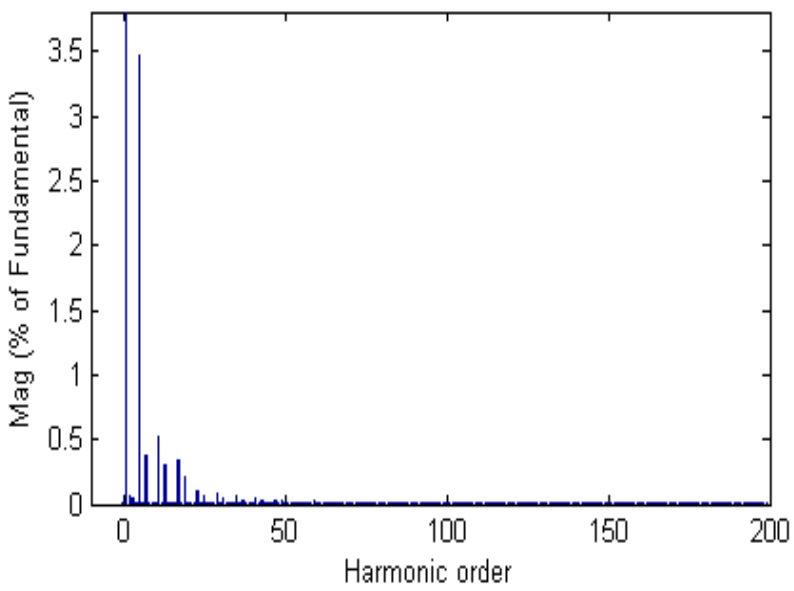

Fig.13. Harmonic spectrum of phase-a source current of test power system with SAF.

Fig .13 shows the harmonic spectrum of the supply current waveform in phase-a. The THD of the supply current in phase-a is $3.56 \%$. From 
Figs. 8 and 13, the THD with SAF is very low compared to without SAF.

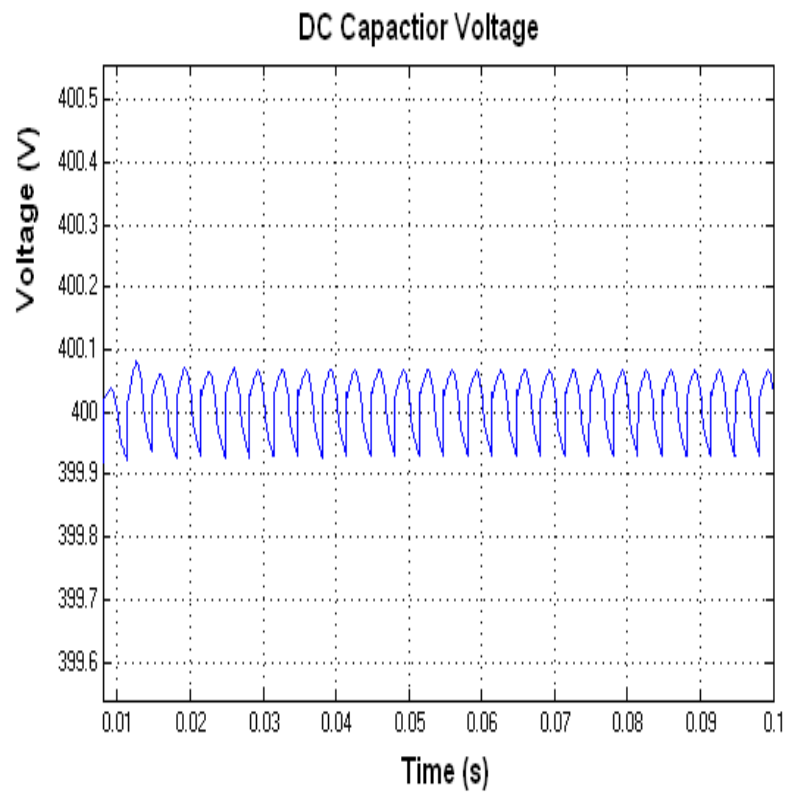

Fig.14. DC Capacitor voltage of SAF.

Fig. 14 shows the constant and small ripple dc capacitor voltage of SAF. It can be found that the DC capacitor voltage of SAF has without startup-transient overshoot with proposed FLCB.

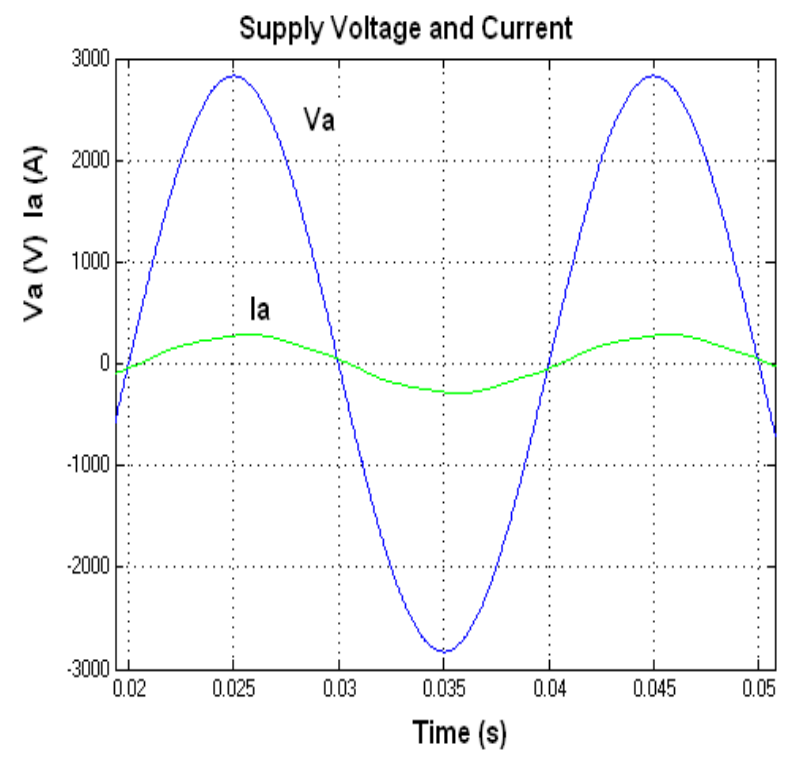

Fig. 15 In-phase source current with supply voltage of phase-a for test power system with SAF.

The source current is in phase with the source voltage as shown in the Fig. 15 (for phase-a only). This implies a near unity power factor operation.

Tables 3 shows the THD analysis of supply currents and voltages $r$ with and without SAF. From the Table 3, THD with SAF is very low compared to without SAF.

Table 3. Total harmonic distortion Analysis of Test Power System.

\begin{tabular}{|c|c|c|c|c|c|c|}
\hline \multirow{2}{*}{$\begin{array}{c}\text { Param } \\
\text { eters }\end{array}$} & \multicolumn{3}{|c|}{ Source current Is } & \multicolumn{3}{|c|}{ Voltage V } \\
\hline & $\mathrm{I}_{\mathrm{a}}$ & $\mathrm{I}_{\mathrm{b}}$ & $\mathrm{I}_{\mathrm{c}}$ & $\mathrm{V}_{\mathrm{a}}$ & $\mathrm{V}_{\mathrm{b}}$ & $\mathrm{V}_{\mathrm{c}}$ \\
\hline $\begin{array}{l}\text { Witho } \\
\text { ut SAF }\end{array}$ & $\begin{array}{c}26.3 \\
5 \%\end{array}$ & $\begin{array}{c}26.35 \\
\%\end{array}$ & $\begin{array}{c}26.35 \\
\%\end{array}$ & $25 \%$ & $25 \%$ & $\begin{array}{l}25 \\
\%\end{array}$ \\
\hline $\begin{array}{l}\text { With } \\
\text { SAF }\end{array}$ & $\begin{array}{l}3.56 \\
\%\end{array}$ & $\begin{array}{c}3.56 \\
\%\end{array}$ & $\begin{array}{c}3.56 \\
\%\end{array}$ & $3.9 \%$ & $3.9 \%$ & $\begin{array}{c}3.9 \\
\%\end{array}$ \\
\hline
\end{tabular}

\section{CONCLUSIONS}

This paper presented a FLCB and an HCPWM technique for SAF has been successfully demonstrated in MatLab/Simulink. The SAF was simulated and its performance was analyzed in a sample power system with a source and a NLDRL. The HCPWM control has successfully eliminated the harmonics and improved the power factor in supply side. The simulation results show the efficiency of the fuzzy logic controller in maintaining the DC voltage set point. Future work, the neuro control technique can be applied to study the proposed system further.

\section{REFERNCES}

[1] Roger C.Dugan, Mark F. McGranaghan, Surya Santoso and H.Wayne Beaty, Electrical Power System Quality, McGraw -Hill.

[2] Bhim Singh, Kamal Al Haddad and Ambrish Chandra, AReview of Active Filters for Power Quality Improvement, IEEE Trans on Industrial Electronics, Vol.46, No.5, October 1999, pp. 960-970.

[3] Zainal Salam, Tan Perng Cheng and Awang Jusoh, Harmonics Mitigation using Active Power Filter: A Technological Review Elekrika, Vol.8, No.2, 2006, 17-26.

[4] Y.Sato, T.Kawase, M.Akiyama, and T.Kataoka, A control strategy for general - purpose active filters based on voltage detection, IEEE Trans. Ind. Appl., vol. 36, no.5, pp.1405-1412, Sep / Oct.2000.

[5] M. Kazmierkowsi, L.Malesani,Current Control Techniques for Three Phase Voltage Source PWM converters: A survey, IEEE Trans on Industrial Electronics, vol.45, no.5, pp.691-703, October 1998.

[6] S. Buso, L. Malesani, P. Mattavelli, Comparison of current control Techniques for Active power Filter Applications, IEEE 
Transactions on Industrial Electronics, Vol.45, no.5, pp.722-729, Oct 1998 .

[7] E.E.EL-Khoy, A. EL-Sabbe, A.El-Hefnawy, and Hamdy M.Mharous, Three phase active power filter based on current controlled voltage source inverter, Electrical Power and Energy Systems, 28 (2006), 537-547.

[8] S.K.Jain, P.Agrawal and H.O.Gupta, Fuzzy Logic controlled shunt active power filter for power quality improvement, IEE proceedings in Electrical Power Applications, Vol 149, No.5, September 2002.

[9] V. Agelidis, M. Calais, Application specific harmonic performance evaluation of multicarrier PWM techniques, IEEEPESC'98 Conference Record, pp. 172-178, 1998.

[10] G. Carrara, S. Gardelta, M. Marchesoni, A new multilevel PWM method: theoretical analysis, IEEE Trans. On power electronics Vol. 7. No. 3, July, pp.497-505, 1992.
G.Jayakrishna received B.Tech and M.Tech degrees in Electrical Engineering from Jawaharlal Nehru Technological University, Hyderabad, India in 1993 and 2004 respectively. Currently he is professor in Electrical and Electronics Engineering department,,Siddharth Institute of Engineering and Technology, Puttur, India. He is Life Member of Indian Society for Technical Education LM 43502. His research interests include Power Systems and Power Quality.

Dr.K.S.R.Anjaneyulu pursued his Engineering education and Ph.D. in Electrical Engineering from Jawaharlal Nehru Technological University, Hyderabad. He joined in the department of Electrical Engineering of JNTU College of Engineering,Anantapur as lecturer in 1985 and presently working as Professor of Electrical Engineering and Director Research and Development Cell, JNTU, Anantapur. He is Fellow of Institution of Engineers (I), Life Member of ISTE and Indian Society of Power Engineers (ISPE). His research interests include Power Systems and Intelligent Techniques. 